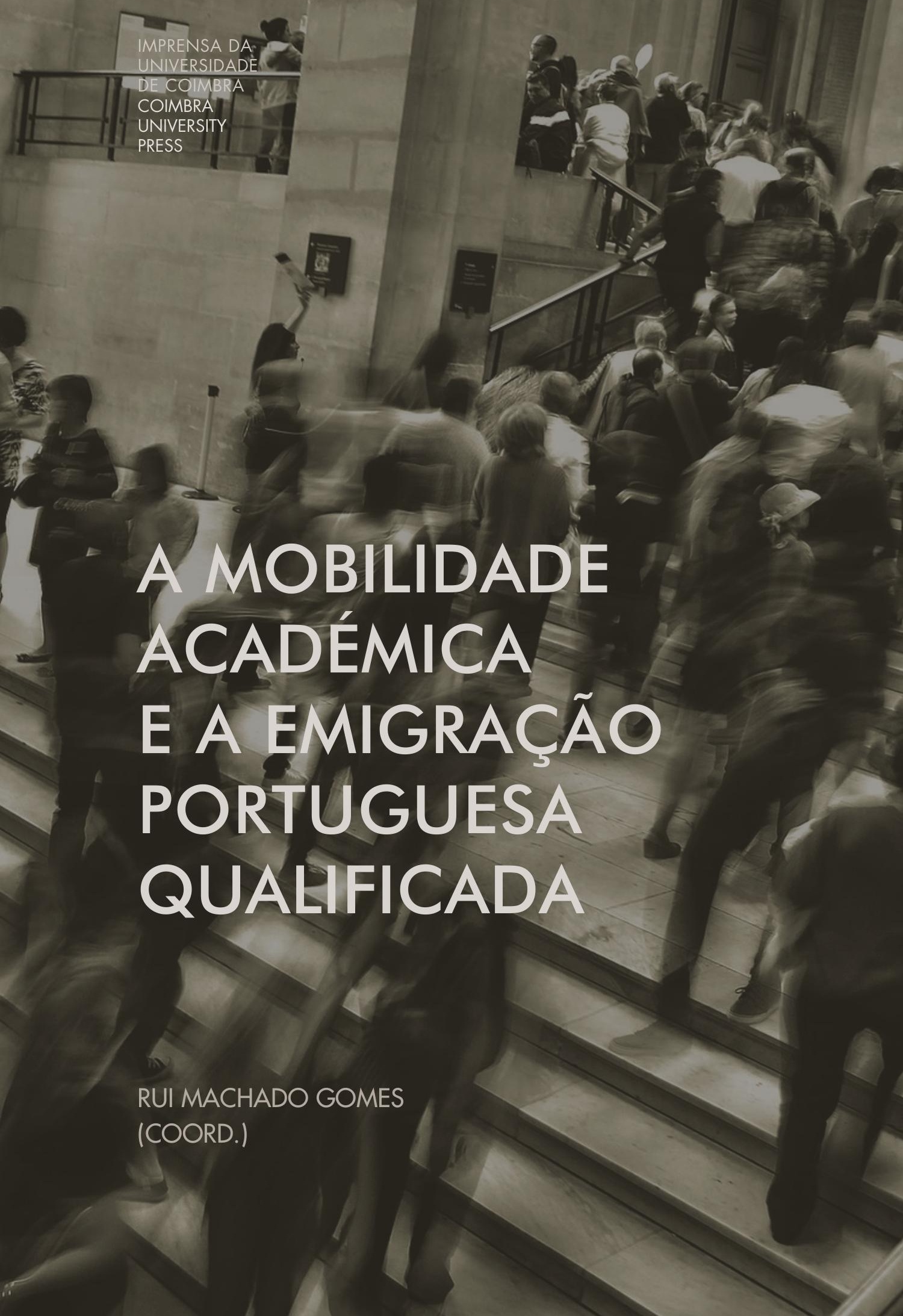




\section{A NOVA EMIGRAÇÃO E A RELAÇÃO \\ COMA SOCIEDADE PORTUGUESA: PERFIS \\ E ESTRATÉGIAS DOS EMIGRANTES \\ MAIS E MENOS QUALIFICADOS}

\section{Introdução}

O texto que agora se apresenta pretende analisar algumas caraterísticas, práticas e aspirações dos emigrantes mais qualificados portugueses, em comparação com os seus compatriotas menos qualificados. Tal como sucede em vários estudos sobre este tema, a fronteira entre os mais e menos qualificados é a posse de um diploma de nível superior. É certo que as "qualificações" transcendem, em larga medida, as competências da educação formal e, em particular, a conclusão de um curso de ensino superior. Desde há muito, porém, que, devido a necessidades de operacionalização ou a limitações de acesso aos dados, se opta por aquela perspetiva para distinguir os emigrantes mais e menos qualificados - ou, mais comummente, os "altamente qualificados" e os que não o são. Esta será também a perspetiva adotada neste estudo.

Os dados empíricos que serão apresentados foram recolhidos no âmbito do projeto "Regresso ao Futuro: A nova emigração e a sua relação com a sociedade portuguesa" (REMIGR), que reuniu investigadores da Universidade

\footnotetext{
${ }^{1}$ Autores: Pedro Candeias (SOCIUS/CSG e IGOT - Universidade de Lisboa); João Peixoto (SOCIUS/CSG, ISEG, Universidade de Lisboa); Joana Azevedo (CIES, ISCTE-IUL); Isabel Tiago de Oliveira (CIES, ISCTE-IUL); Bárbara Ferreira (CEG/IGOT e CIES, ISCTE-IUL); Alexandra Ferro (CIES, ISCTE-IUL); José Carlos Marques (CICS.NOVA e CES, Universidade de Coimbra); Pedro Góis (CES, Universidade de Coimbra); Jorge Macaísta Malheiros (CEG/IGOT, Universidade de Lisboa); Paulo Miguel Madeira (CEG/IGOT, Universidade de Lisboa); Aline Schiltz (CEG/IGOT, Universidade de Lisboa); Eugénio Santana (CEG/IGOT, Universidade de Lisboa).
} 
de Lisboa, Universidade de Coimbra e ISCTE-Instituto Universitário de Lisboa. O projeto, financiado pela Fundação para a Ciência e a Tecnologia (PTDC/ ATP-DEM/5152/2012), decorreu entre 2013 e 2015. Uma vez que este texto foi produzido no período de divulgação dos resultados definitivos do projeto, ele adota uma abordagem sobretudo descritiva. $\mathrm{O}$ aprofundamento da informação apresentada será efetuado noutros contextos.

\section{Enquadramento}

Na última década tem-se vindo a observar um crescente interesse pelos estudos da emigração portuguesa qualificada ou altamente qualificada. Alguns trabalhos mais abrangentes analisam o fenómeno à luz da teoria do brain drain (Delicado \& Alves, 2013; Emília \& Ferreira, 2013; Gomes et al., 2015). Outros analisaram o discurso mediático sobre o tema (Cogo \& Badet, 2013; Emília \& Ferreira, 2013). Também foi estudado o impacto que o fenómeno tem em Portugal (Faria, 2012). Uma obra recente dedicou-se a este tipo de emigração para um país em particular - França (Lopes, 2014) e com um escopo mais abrangente foi analisada esta emigração com destino à Europa (Azevedo, 2014). Contudo, mais frequentes têm sido os estudos dedicados a um grupo profissional específico, como os profissionais de saúde (Pereira, Pinto \& Pires, 2015; Ribeiro et al., 2013), professores e leitores de português (Pereira, 2007) e, especialmente, académicos e alunos de doutoramento (Araújo, 2007; Delicado, 2010, 2011; Delicado \& Alves, 2013; Fontes, 2007; Fontes \& Araújo, 2013).

O ponto em comum dos trabalhos supracitados é todos eles tomarem como unidade de análise o subgrupo dos emigrantes detentores de um grau académico de nível superior, habitualmente designados por emigrantes qualificados. Não tem sido examinado em detalhe, pelo menos de forma explícita, o universo dos emigrantes detentores de menores qualificações, incluindo aqueles cujo domínio de qualificações profissionais (não académicas), médias ou elevadas, é considerável. O facto de a emigração não ter sido objeto de estudo sistemático em Portugal nos últimos anos contribui para alguma invisibilização deste fenómeno (Candeias, Ferreira, \& Peixoto, 2014; Malheiros, 2010; Marques, 2010; Peixoto, 2012). Em paralelo, o aumento do mediatismo 
da emigração mais qualificada, em particular dos jovens licenciados no contexto da crise atual, explicará também parcialmente a maior 'saliência' deste objeto de estudo nos últimos anos.

Com este texto, pretende-se deslocar a análise com enfoque nos emigrantes mais qualificados para uma análise comparativa, em que a posição deste grupo é contrastada com a dos emigrantes menos qualificados - isto é, dos que não apresentam uma escolarização do nível terciário. Nos próximos pontos, depois de uma secção metodológica, serão tidos em conta indicadores do perfil sociodemográfico destes sujeitos, da sua trajetória migratória, da sua integração nos países de destino e das relações que mantêm ou tencionam manter com Portugal no futuro.

\section{Metodologia}

O material empírico de suporte a este texto provém do projeto "Regresso ao Futuro: A nova emigração e a sua relação com a sociedade portuguesa" (REMIGR). O objetivo principal deste projeto foi traçar o perfil da emigração portuguesa mais recente - indivíduos nascidos em Portugal ou com nacionalidade portuguesa que saíram do país a partir do ano 2000 (inclusive) - e as suas relações com o país de origem. Uma das particularidades do projeto foi o de procurar abranger tanto emigrantes mais qualificados como menos qualificados. Este procedimento permite estabelecer um grupo de referência, não analisando os subgrupos dos mais ou menos qualificados por si só.

Neste texto são apresentados os resultados de um inquérito aplicado segundo uma abordagem mista, ou de mixed-modes surveys (cf. Dillman, Smyth, \& Christian, 2014, cap. 11), que combinou inquéritos online com inquéritos em formato de papel-e-caneta. Os primeiros recolheram respostas oriundas de mais de 100 países. Os inquéritos por questionário na versão tradicional foram aplicados em seis países: França, Luxemburgo, Reino Unido, Brasil, Angola e Moçambique. O processo de inquirição decorreu entre 6 de maio de 2014 e 25 de maio de 2015. Foram validados, após depuração, 6.086 questionários. Destes, $73 \%$ foram recolhidos via internet, através do website criado para o efeito (www.remigr.pt). 
Para o presente texto, consideram-se como emigrantes "mais qualificados" aqueles com grau académico de nível superior e como emigrantes "menos qualificados" os que se encontram abaixo deste patamar. Deste modo, o exercício será comparar os inquiridos com bacharelato, licenciatura, mestrado ou doutoramento $(n=4.263)$, tendo como categoria de referência os inquiridos com escolaridade de nível secundário ou inferior $(n=1.805)$. Uma versão desagregada destas qualificações encontra-se na Tabela 1.

TABELA 1: Níveis de escolaridade

\begin{tabular}{|l|c|c|}
\cline { 2 - 3 } \multicolumn{1}{c|}{} & $\mathrm{n}$ & $\%$ \\
\hline Nenhum & 11 & 0,2 \\
$2 .^{\circ}$ Ciclo EB $1 .^{\circ}$ Ciclo EB & 99 & 1,6 \\
$3 .^{\circ}$ Ciclo EB & 168 & 2,8 \\
Secundário & 405 & 6,7 \\
Licenciatura/Bacharelato & 1.122 & 18,5 \\
Mestrado & 2.392 & 39,4 \\
Doutoramento & 1.553 & 25,6 \\
Total & 318 & 5,2 \\
\hline
\end{tabular}

Fonte: Inquérito aos Portugueses no Estrangeiro - Projeto REMIGR

O peso dos respondentes com escolarização mais elevada foi uma consequência esperada da aplicação do inquérito online e, também, da estratégia de divulgação desta forma de inquirição, que privilegiou as redes em que a presença dos mais qualificados é dominante. Também por isso se explica que entre os "menos qualificados" predominem indivíduos com o ensino secundário completo. Um dos objetivos da realização de inquéritos tradicionais em seis países foi, precisamente, tentar corrigir o enviesamento da amostra, permitindo chegar a um universo mais próximo da realidade migratória - que se sabe continuar a ser dominada por emigrantes com escolarização pouco elevada (cf. Pires, Pereira, Azevedo, \& Ribeiro, 2014; Pires et al., 2015) ${ }^{2}$.

2 Segundo o Observatório da Emigração, a taxa bruta de emigração dos mais qualificados era de $10,7 \%$ em 2001 e de $10,6 \%$ em 2011, o que mitiga a hipótese de um brain 
Refira-se ainda, de novo, que a opção teórica e metodológica de separar os emigrantes "mais e menos qualificados" pela escolarização de nível superior é assumidamente redutora e incompleta: redutora, uma vez que reduz o conceito de qualificação a níveis escolares ou académicos; incompleta, pois não contempla qualquer indicador de qualificação profissional.

Mesmo tendo em conta a não representatividade da amostra e o enquadramento dos níveis de qualificação profissional, acredita-se que os resultados são interessantes e significativos, dada a quase inexistência de estudos comparativos entre os perfis de emigrantes mais e menos qualificados em Portugal.

\section{Resultados}

\section{Perfil sociodemográfico}

No que respeita à distribuição por sexo e idade (Tabela 2), a amostra dos emigrantes mais qualificados apresenta-se muito equilibrada entre os sexos, com um peso superior das mulheres por apenas dois pontos percentuais. Já nos emigrantes com qualificações escolares mais reduzidas a preponderância é masculina, com uma relação de perto de 60/40 a favor dos homens. Estes dados parecem refletir, por um lado, a realidade da emigração tradicional menos qualificada, com maior peso dos homens. Por outro lado, refletem também a estrutura da população portuguesa, onde as mulheres são ligeiramente mais qualificadas que os homens ${ }^{3}$. Quanto à idade, tal como na estrutura da população portuguesa, os inquiridos menos qualificados são ligeiramente mais velhos do que os mais qualificados, com médias de 37 e 34 anos, respetivamente.

drain massivo neste período. Por sua vez, a OCDE e as Nações Unidas (OECD-UN-DESA, 2013) revelam uma taxa ligeiramente superior, na ordem de $12,9 \%$, com base nos Censos de 2010/11. Todavia, sublinha-se que estes dados se referem ao período censitário, pelo que podem não ter captado o eventual crescimento acelerado das saídas de qualificados ocorrido desde então.

3 ver http://www.pordata.pt/Portugal/População+residente++segundo+os+Censos++com+o +ensino+superior+completo+em+percentagem+da+população+residente+total+e+por+sexo-677 
TABELA 2: Distribuição por sexo

\begin{tabular}{|l|c|c|c|c|}
\cline { 2 - 5 } \multicolumn{1}{c|}{} & \multicolumn{2}{c|}{ Mais qualificados } & \multicolumn{2}{c|}{ Menos qualificados } \\
\hline & $\mathrm{n}$ & $\%$ & $\mathrm{n}$ & $\%$ \\
\hline Masculino & 2.089 & 49,0 & 1.072 & 59,5 \\
\hline Feminino & 2.173 & 51,0 & 731 & 40,5 \\
\hline Total & 4.262 & 100,0 & 1.803 & 100,0 \\
\hline
\end{tabular}

Fonte: Inquérito aos Portugueses no Estrangeiro - Projeto REMIGR

\section{Trajetória migratória}

Os indicadores escolhidos para ilustrar a trajetória migratória dos grupos em análise foram os países de destino, os fatores que os levaram a sair de Portugal, bem como a existência de uma experiência emigratória prévia.

\section{Principais países de destino}

Os países de destino dos inquiridos que compõem a amostra (Tabela 3) são dotados tanto de diferenças como de similaridades. Uma das similaridades posiciona o Reino Unido como o principal destino, independentemente do nível de qualificação em análise. Este é o destino de mais de 1/4 dos mais qualificados e de mais de $1 / 5$ dos menos qualificados. A segunda concordância entre ambas as amostras é a predominância de destinos europeus. Contudo, a amostra menos qualificada apresenta maior incidência no velho continente, onde $76 \%$ dos inquiridos se encontravam; na amostra mais qualificada a proporção é de $62 \%$.

TABela 3: Principais países de destino

\begin{tabular}{|l|c|c|l|c|c|}
\hline \multicolumn{3}{|c|}{ Mais qualificados } & \multicolumn{3}{c|}{ Menos qualificados } \\
\hline & $\mathrm{n}$ & $\%$ & & $\mathrm{n}$ & $\%$ \\
\hline Reino Unido & 1.035 & 24,3 & Reino Unido & 413 & 22,9 \\
\hline Brasil & 402 & 9,4 & França & 368 & 20,4 \\
\hline Angola & 396 & 9,3 & Luxemburgo & 252 & 14,0 \\
\hline
\end{tabular}




\begin{tabular}{|l|c|c|l|c|r|}
\hline \multicolumn{3}{|c|}{ Mais qualificados } & \multicolumn{3}{c|}{ Menos qualificados } \\
\hline Moçambique & 324 & 7,6 & Angola & 180 & 10,0 \\
\hline Alemanha & 290 & 6,8 & Brasil & 94 & 5,2 \\
\hline França & 226 & 5,3 & Moçambique & 90 & 5,0 \\
\hline Suíça & 151 & 3,5 & Alemanha & 79 & 4,4 \\
\hline Bélgica & 135 & 3,2 & Suíça & 71 & 3,9 \\
\hline Holanda & 124 & 2,9 & Holanda & 35 & 1,9 \\
\hline Luxemburgo & 114 & 2,7 & Bélgica & 26 & 1,4 \\
\hline Outros & 1.066 & 25,0 & Outros & 197 & 10,9 \\
\hline Total & 4.263 & 100,0 & Total & 1.805 & 100,0 \\
\hline
\end{tabular}

Fonte: Inquérito aos Portugueses no Estrangeiro - Projeto REMIGR

Deve notar-se que a distribuição por países é reflexo, em grande parte, dos seis países que foram escolhidos para estudos de caso e que tiveram, para além da possibilidade de resposta online, um inquérito a decorrer no terreno. Por este motivo, importa destacar os países que não faziam parte dos estudos de caso selecionados e que se encontram, ainda assim, no top dos principais destinos: Alemanha, Suíça, Holanda e Bélgica.

Independentemente das questões metodológicas envolvidas, o forte peso dos destinos europeus em toda a mobilidade internacional portuguesa recente é um dado adquirido. O regime de livre circulação no interior da União Europeia, a proximidade geográfica, as redes sociais e as redes ativas de recrutamento são os principais fatores explicativos.

\section{Fatores de repulsão}

Um conjunto de variáveis que importa comparar diz respeito aos motivos pelos quais os inquiridos saíram de Portugal (Figura 1). A maior diferença entre os mais e menos qualificados reside no item "realizar novas experiências", que recolheu $41 \%$ das respostas no grupo dos mais qualificados vis-à-vis $23 \%$ no grupo dos menos qualificados. A predominância dos valores neste item pode remeter para motivações que podem ser classificadas como pós-materialistas, na terminologia de Inglehart (1977, 1990). As motivações 
pós-materialistas já tinham sido constatadas nas gerações mais jovens de emigrantes croatas (Colic-Peisker, 2008), ou no estudo de médicos espanhóis no Reino Unido (Blitz, 2014, cap. 4) ${ }^{4}$.

FIGURA 1: Fatores de repulsão

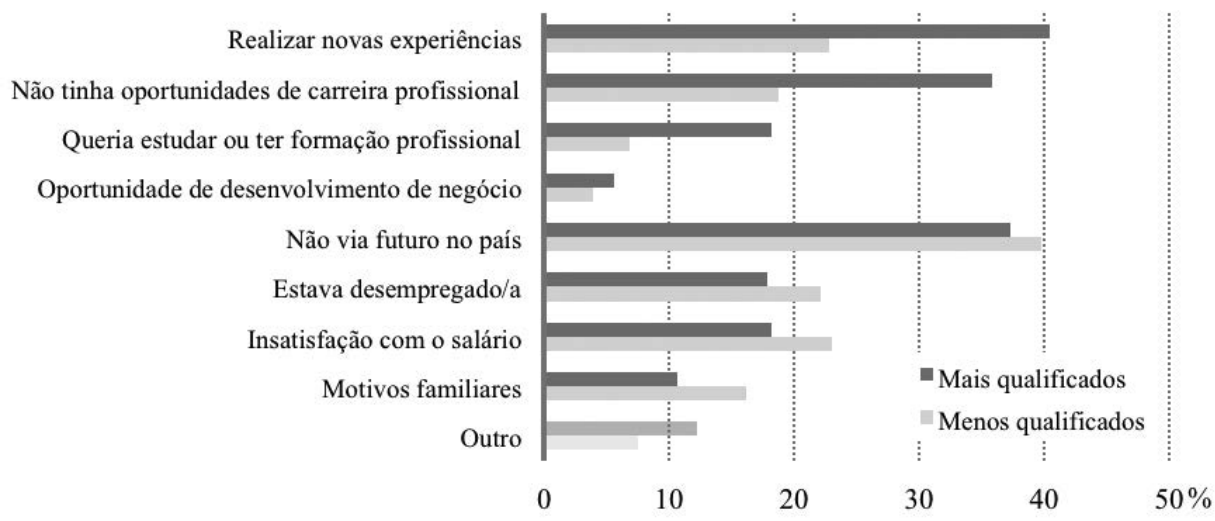

Fonte: Inquérito aos Portugueses no Estrangeiro - Projeto REMIGR

Nota: Ordenado pela grandeza da diferença entre os mais qualificados e os menos qualificados

Outros fatores que se mostraram mais relevantes para o grupo dos emigrantes mais qualificados são as expetativas em relação ao futuro ("não via futuro no país") e as motivações que remetem para a dimensão da realização profissional, seja a inexistência de oportunidades de carreira ou a vontade de adquirir formação escolar ou profissional.

Em contrapartida, os motivos em que mais se destacam os emigrantes menos qualificados são igualmente as baixas expetativas em relação ao futuro (cerca de $40 \%$ dos inquiridos assinalaram este item) ${ }^{5}$ e a realização de novas

${ }^{4}$ Segundo a proposta de Inglehart, os valores pós-materialistas tendem a regredir em situações de crise e incerteza (que conduzem ao reforço dos valores materialistas) e a reforçar-se em situações de segurança económica. Os resultados, interpretados segundo esta, revelam um paradoxo: os emigrantes qualificados (e não só) parecem optar por sair do país, não porque se encontram numa situação marcada por fortes incertezas, mas porque se sentem economicamente seguros e, por isso, privilegiam valores pós-materialistas.

5 As respostas dos dois grupos em relação a este tema são da mesma ordem de grandeza, com apenas mais alguns pontos percentuais para os menos qualificados. Talvez este aspeto seja o principal "fator comum" aos dois grupos. 
experiências, mas também a insatisfação com o salário e as situações de desemprego.

Analisando as motivações pelas quais o grupo dos mais qualificados se destaca pelas baixas proporções relativas, enunciam-se as motivações familiares, a insatisfação salarial e as situações de desemprego. Os valores mais reduzidos nas motivações familiares parecem indicar que a emigração mais qualificada se enquadra num projeto individual. O segmento mais qualificado tende a sair do país sozinho (56\% versus 46\%). Também associada se encontra uma proporção mais elevada de solteiros (48\% versus 33\%). Tanto o estado civil como a estratégia de emigrar sozinho podem ser resultado do perfil etário mais jovem, como já foi referido.

\section{Experiência emigratória}

Quando se compara a experiência emigratória anterior entre ambos os grupos (Tabela 4), a primeira conclusão é a de que, independentemente do grupo, a tendência é de se estar perante a primeira experiência emigratória dos sujeitos. Contudo, é no grupo dos mais qualificados que a proporção de emigrantes com anteriores experiências migratórias é mais elevada: 38\%, em comparação com $24 \%$ dos menos qualificados. No grupo dos mais qualificados, algumas destas experiências podem remeter para experiências académicas realizadas, por exemplo, no âmbito do programa Erasmus e outros similares.

TABELA 4: Experiência emigratória anterior

\begin{tabular}{|l|c|c|c|c|}
\cline { 2 - 5 } \multicolumn{1}{c|}{} & \multicolumn{2}{c|}{ Mais qualificados } & \multicolumn{2}{c|}{ Menos qualificados } \\
\hline & $\mathrm{N}$ & $\%$ & $\mathrm{n}$ & $\%$ \\
\hline Sim & 1.594 & 38,1 & 431 & 24,1 \\
\hline Não & 2.590 & 61,9 & 1.355 & 75,9 \\
\hline Total & 4.184 & 100,0 & 1.786 & 100,0 \\
\hline
\end{tabular}

Fonte: Inquérito aos Portugueses no Estrangeiro - Projeto REMIGR 


\section{Integração}

Para analisar a integração diferenciada dos sujeitos em análise nos países de destino, foram comparados os setores de atividade laboral em dois momentos no tempo, bem como as respostas a uma bateria de indicadores referentes às dificuldades de integração vivenciadas.

\section{Setores de atividade}

A comparação longitudinal dos setores de atividade laboral (Tabela 5) permite conhecer as alterações que podem ter ocorrido na trajetória profissional dos sujeitos que se analisam.

TABELA 5: Comparação longitudinal dos setores de atividade (\%)

\begin{tabular}{|l|c|c|c|c|}
\cline { 2 - 5 } \multicolumn{1}{c|}{} & \multicolumn{2}{c|}{ Mais qualificados } & \multicolumn{2}{c|}{ Menos qualificados } \\
\cline { 2 - 5 } \multicolumn{1}{c|}{} & Portugal & Atualmente & Portugal & Atualmente \\
\hline Indústria & 9,3 & 11,5 & 14,2 & 12,9 \\
\hline Construção & 11,6 & 11,7 & 18,8 & 19,5 \\
\hline $\begin{array}{l}\text { Comércio, alojamento e restauração, } \\
\text { transportes }\end{array}$ & 10,1 & 9,0 & 30,2 & 26,2 \\
\hline $\begin{array}{l}\text { Atividades financeiras, serviços às } \\
\text { empresas }\end{array}$ & 16,9 & 17,6 & 8,3 & 9,3 \\
\hline Educação & 16 & 12,9 & 4,0 & 3,3 \\
\hline Saúde & 9,4 & 11,6 & 2,8 & 2,4 \\
\hline $\begin{array}{l}\text { Atividades pessoais, familiares } \\
\text { e domésticas }\end{array}$ & 1,2 & 1,8 & 3,7 & 8,8 \\
\hline Outra situação & 25,6 & 23,8 & 18,0 & 17,7 \\
\hline Total & 100,0 & 100,0 & 100,0 & 100,0 \\
\hline
\end{tabular}

Fonte: Inquérito aos Portugueses no Estrangeiro - Projeto REMIGR

No caso dos mais qualificados, existia e existe uma maior dispersão pelos diversos setores. Verifica-se apenas um peso mais reduzido nas atividades 
pessoais e domésticas. Em Portugal, este grupo laborava, em grande parte, no setor da educação e nas atividades financeiras e serviços às empresas. Um terço da amostra mais qualificada encontrava-se ocupada nestes dois setores quando residia em Portugal. Embora ambos continuassem a ser os mais frequentes, observa-se atualmente uma maior concentração no último, com cerca de $18 \%$ dos emigrantes qualificados. O grande peso das "outras situações" (quer em Portugal, quer no país de destino, representam cerca de 25\%), que incluem situações difíceis de classificar, coloca, porém, alguns obstáculos à análise.

Já no segmento menos qualificado da amostra predominavam, em Portugal, os trabalhos associados aos serviços de comércio, de alojamento, de restauração e transportes, com 30\%, bem como o setor da construção civil e obras públicas, com 19\%. No país de destino estes dois setores continuavam a ocupar o topo da ordenação.

Com uma análise ao nível individual, que classifica a trajetória dos sujeitos entre estacionária (quando o setor de atividade se mantém nos dois momentos) ou de mudança (quando as áreas de atividade não coincidem entre os dois momentos), observa-se uma maior mudança nos setores de atividade no grupo dos menos qualificados. A taxa de estacionariedade que foi calculada assume valores na ordem dos $65 \%$ no segmento mais qualificado, enquanto no grupo menos qualificado o valor é de $53 \%$.

\section{Dificuldades de integração}

Grande parte dos problemas de integração com que os emigrantes inquiridos se deparam diferem de acordo com o seu nível de qualificação (Tabela 6). As diferenças com relevância estatística mais elevada dizem respeito ao acesso aos serviços de saúde e à dificuldade em lidar com o aparato administrativo, com valores mais elevados no segmento de qualificações superiores. Note-se, porém, que existe uma proporção relativamente maior de emigrantes mais qualificados em países como Angola e Moçambique, em que o acesso a serviços de saúde pode ser mais difícil. E, por se tratar de países fora do espaço Schengen, a necessidade de visto e da sua renovação pode pesar no item "burocracias". 
TABELA 6: Dificuldades de integração, médias

\begin{tabular}{|l|c|c|c|}
\cline { 2 - 4 } \multicolumn{1}{c|}{} & $\begin{array}{c}\text { Mais } \\
\text { qualificados }\end{array}$ & $\begin{array}{c}\text { Menos } \\
\text { qualificados }\end{array}$ & Diferença \\
\hline Dificuldades de acesso aos cuidados de saúde & 2,2 & 1,9 & 0,3 \\
\hline Burocracias & 2,9 & 2,7 & 0,2 \\
\hline Integração dos filhos na escola & 1,9 & 1,8 & 0,1 \\
\hline Obtenção de apoios sociais & 2,4 & 2,3 & 0,1 \\
\hline Dificuldades para alugar uma casa ou apartamento & 2,9 & 2,8 & 0,1 \\
\hline Poucos amigos ou solidão & 2,5 & 2,4 & 0,1 \\
\hline Custo de vida & 3,3 & 3,4 & $-0,1$ \\
\hline Dificuldades em encontrar emprego & 2,0 & 2,2 & $-0,2$ \\
\hline Clima & 2,6 & 2,7 & $-0,1$ \\
\hline Discriminação/racismo & 2,0 & 2,2 & $-0,2$ \\
\hline Língua/problemas com o idioma & 2,2 & 2,5 & $-0,3$ \\
\hline
\end{tabular}

Fonte: Inquérito aos Portugueses no Estrangeiro - Projeto REMIGR

Escala: 1: nada difícil, 5: muito difícil;

Os emigrantes menos qualificados destacam-se dos mais qualificados pelos valores mais elevados nos itens referentes à discriminação social e aos problemas com a língua do país de destino. No primeiro caso, interessa procurar fatores relacionados com estes valores, uma vez que, de acordo com as teorias da perceção de discriminação (Taylor, Wright, Moghaddam, \& Lalonde, 1990), seriam os grupos mais desfavorecidos aqueles com menor perceção de discriminação - situação que os dados não confirmam. Os problemas sentidos pelos emigrantes portugueses mais desqualificados em alguns países europeus poderão explicar estas respostas. Já as dificuldades com a língua do país de destino podem ter duas ordens de explicações associadas: por um lado, a maior concentração de emigrantes não qualificados em países cuja língua oficial não é o português; por outro, uma questão de literacia, pois as qualificações escolares mais reduzidas estarão associadas a um menor domínio de línguas estrangeiras.

No sentido contrário, observa-se que os emigrantes mais qualificados dão maior importância às dificuldades nas questões burocráticas e na área do acesso à saúde. No primeiro caso, os problemas deverão resultar do facto de 
os países de destino serem muitas vezes não europeus, o que torna difíceis os processos de legalização e de reconhecimento de diplomas. No segundo, os problemas deverão ser causados pelo facto de os sistemas universais de saúde não estarem tão desenvolvidos naqueles países.

\section{Transnacionalismo}

No que diz respeito às relações que os emigrantes mantêm com Portugal - ou transnacionalismo - são apresentados os resultados das questões respeitantes ao envio de remessas, visitas a casa, utilização dos media para comunicar e obter informações sobre Portugal, participação na esfera política e planos para o futuro.

\section{Remessas}

O envio de remessas assume proporções muito semelhantes entre os dois grupos, dividindo quase em duas partes idênticas ambas as amostras (50\% dos mais qualificados e $51 \%$ dos menos qualificados enviam remessas). Contudo, o envio de remessas assume ritmos e volumes distintos de acordo com as qualificações dos inquiridos (Tabela 7).

No caso dos menos qualificados, o envio de remessas é efetuado com uma periodicidade, no mínimo, mensal por $50 \%$ dos inquiridos. Este tipo de periodicidade muito curta é mais baixa nos mais qualificados, para os quais a proporção se cinge a 36\%. Para estes emigrantes, a situação mais frequente é o envio de remessas apenas algumas vezes por ano.

Mas a diferenciação está patente também no volume que as remessas assumem $^{6}$. Se para o grupo dos mais qualificados as remessas assumem uma média mensal de $985 €$, os menos qualificados enviam valores na ordem dos $803 €$. Mais de um terço dos emigrantes mais qualificados que enviam remessas indi-

\footnotetext{
${ }^{6}$ No questionário pedia-se aos inquiridos para assinalarem a média mensal das remessas, independentemente da periodicidade. As médias foram então calculadas através do ponto intermédio de cada escalão.
} 
cam valores superiores a $1000 €$ mensais. Por seu lado, o escalão com menores qualificações encontra-se dividido essencialmente entre os 251 a $500 €$ mensais e os mais de $1.000 €$ mensais ( $25 \%$ e $24 \%$, respetivamente). Ou seja, enquanto os menos qualificados enviam mais frequentemente menores valores, os mais qualificados enviam, não com tanta frequência, valores mais avultados.

TABELA 7: Periodicidade e montante mensal das remessas

\begin{tabular}{|l|c|c|c|c|}
\cline { 2 - 5 } \multicolumn{1}{c|}{} & \multicolumn{2}{c|}{ Mais qualificados } & \multicolumn{2}{c|}{ Menos qualificados } \\
\cline { 2 - 5 } \multicolumn{1}{c|}{} & $\mathrm{n}$ & $\%$ & $\mathrm{n}$ & $\%$ \\
\hline Uma ou mais vezes por mês & 692 & 35,7 & 408 & 50,2 \\
\hline Algumas vezes por ano & 800 & 41,3 & 212 & 26,1 \\
\hline Quando tem possibilidade & 445 & 23,0 & 193 & 23,7 \\
\hline Total & 1.937 & 100,0 & 813 & 100,0 \\
\hline Até $€ 100$ & 155 & 8,2 & 89 & 11,2 \\
\hline$€ 101-€ 250$ & 276 & 14,7 & 153 & 19,3 \\
\hline$€ 251-€ 500$ & 369 & 19,6 & 198 & 24,9 \\
\hline$€ 501-€ 1000$ & 389 & 20,7 & 160 & 20,2 \\
\hline Mais de $€ 1000$ & 690 & 36,7 & 194 & 24,4 \\
\hline Total & 1.879 & 100,0 & 794 & 100,0 \\
\hline
\end{tabular}

Fonte: Inquérito aos Portugueses no Estrangeiro - Projeto REMIGR

Nota: Valores calculados tendo como base os inquiridos que declararam ter enviado remessas no último ano.

\section{Visitas a casa}

As visitas a Portugal (Tabela 8) são mais frequentes no grupo com qualificações mais elevadas. Cerca de $30 \%$ dos mais qualificados visitam Portugal pelo menos uma vez a cada três meses. Se o período temporal for estendido até aos seis meses, o acumulado atinge os 64\%. Já no grupo menos qualificado, apenas $14 \%$ visita o país com uma frequência inferior a três meses e $37 \%$ com uma frequência inferior a seis meses. Para estes emigrantes, a situação mais frequente é a visita anual, protagonizada por $41 \%$. Os rendimentos mais elevados e a possibilidade de as empresas pagarem as viagens dos mais qualificados explicarão estas diferenças. 
TABELA 8: Frequência das visitas a Portugal

\begin{tabular}{|l|c|c|c|c|}
\cline { 2 - 5 } \multicolumn{1}{c|}{} & \multicolumn{2}{c|}{ Mais qualificados } & \multicolumn{2}{c|}{ Menos qualificados } \\
\cline { 2 - 5 } \multicolumn{1}{c|}{} & $\mathrm{n}$ & $\%$ & $\mathrm{n}$ & $\%$ \\
\hline Pelo menos uma vez por mês & 137 & 3,5 & 46 & 2,8 \\
\hline Pelo menos uma vez a cada três meses & 1.040 & 26,6 & 185 & 11,4 \\
\hline Pelo menos uma vez a cada seis meses & 1.330 & 34,0 & 362 & 22,3 \\
\hline Pelo menos uma vez por ano & 1.038 & 26,5 & 666 & 41,1 \\
\hline Menos frequentemente & 303 & 7,7 & 274 & 16,9 \\
\hline Nunca & 68 & 1,7 & 89 & 5,5 \\
\hline Total & 3.916 & 100,0 & 1.622 & 100,0 \\
\hline
\end{tabular}

Fonte: Inquérito aos Portugueses no Estrangeiro - Projeto REMIGR

FIGURA 2: Frequência de práticas transnacionais
5 média
Muito qualificados
Menos qualificados

4

3

2

Assistir a canais de Ouvir programas de Ler jornais portugueses Comunicar com a televisão portugueses rádio portugueses (em papel ou online) família ou amigos em online Portugal

Fonte: Inquérito aos Portugueses no Estrangeiro - Projeto REMIGR

Escala:1-nunca, 5-diariamente

\section{Utilização dos media}

A utilização dos media com o objetivo de manter os laços com Portugal também assume diferentes intensidades de acordo com os graus de qualificação dos inquiridos (Figura 2). No entanto, a hierarquia apontada por cada grupo não é muito distante. O mais frequente, para ambos, é a comunicação com familiares ou amigos que se encontram em Portugal. O menos frequente, 
em ambos os grupos, é o acompanhamento de programas de rádio online. A diferença entre os dois grupos está associada às práticas que ocupam uma posição intermédia: enquanto os mais qualificados tendem a consumir com mais frequência jornais portugueses (em papel ou online), os inquiridos com qualificações inferiores preferem assistir a canais de televisão portugueses.

\section{Práticas políticas}

Se forem analisados indicadores de práticas transnacionais relacionados com a participação política (Figura 3), a comparação atribui aos emigrantes mais qualificados maior atividade na esfera pública. Embora a hierarquia não seja muito distinta, os valores médios são sempre superiores no caso dos inquiridos com qualificação académica superior. Em todos os casos, a participação passiva (ouvir e ler notícias) predomina sobre a ativa (votar em eleições no país de origem ou de destino). A maior diferença entre os dois grupos é observada na participação eleitoral no país de origem ${ }^{7}$.

FIGURA 3: Frequência de práticas transnacionais políticas

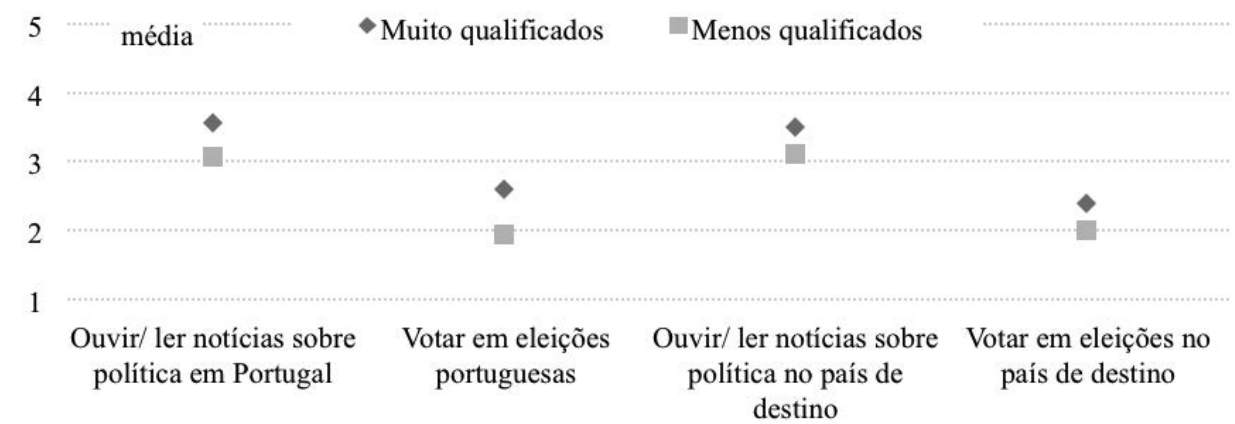

Fonte: Inquérito aos Portugueses no Estrangeiro - Projeto REMIGR

Escala:1-nunca, 2-raramente, 3-ocasionalmente, 4-frequentemente, 5-sempre que possível

7 Pode ter acontecido, porém, que uma parte dos inquiridos que emigraram mais recentemente não tenha tido oportunidade de participar em atos eleitorais no país de origem, porque desde o momento em que saíram não ocorreu nenhuma eleição em Portugal. 


\section{Planos para o futuro}

Por fim, é comparado o escopo dos inquiridos no que respeita ao seu futuro, que se apresenta bastante diversificado (Tabela 9). Cerca de 1/3 dos emigrantes qualificados não têm planos definidos para o futuro, sendo esta indecisão a situação mais frequente neste grupo. Já nos menos qualificados as opiniões distribuem-se entre a intenção de permanência definitiva no destino (35\%) e o regresso a Portugal (32\%). Os dois grupos distinguem-se também nos planos de onward migration (emigrar para outro país), expressos por $14 \%$ dos emigrantes mais qualificados, proporção que mais do que duplica face à encontrada no grupo menos qualificado (6\%).

TABELA 9: Planos para o futuro

\begin{tabular}{|l|c|c|c|c|}
\cline { 2 - 5 } \multicolumn{1}{c|}{} & \multicolumn{2}{c|}{ Mais qualificados } & \multicolumn{2}{c|}{ Menos qualificados } \\
\cline { 2 - 5 } \multicolumn{1}{c|}{} & $\mathrm{n}$ & $\%$ & $\mathrm{n}$ & $\%$ \\
\hline Ficar neste país & 955 & 24,6 & 563 & 34,8 \\
\hline $\begin{array}{l}\text { Ficar neste país um tempo e depois regressar } \\
\text { a Portugal }\end{array}$ & 1.091 & 28,1 & 509 & 31,5 \\
\hline Emigrar para um outro país & 531 & 13,7 & 91 & 5,6 \\
\hline Ainda não tenho planos definidos & 1.299 & 33,5 & 454 & 28,1 \\
\hline Total & 3.876 & 100,0 & 1.617 & 100,0 \\
\hline
\end{tabular}

Fonte: Inquérito aos Portugueses no Estrangeiro - Projeto REMIGR

\section{Conclusão}

Com este texto, pretendeu-se comparar a situação dos emigrantes portugueses recentes, isto é, os indivíduos naturais ou nacionais de Portugal que deixaram o país a partir do ano 2000 , tendo como critério diferenciador o seu nível de qualificação académica. Foram classificados como emigrantes "mais qualificados" os detentores de um grau académico superior e como "menos qualificados" os que estão abaixo desse patamar.

Os resultados apresentados devem ser interpretados com algumas ressalvas. Em primeiro lugar, não se trata de um retrato fiel da emigração portuguesa, 
uma vez que não foram cumpridos critérios de aleatoriedade e representatividade da amostra. Em segundo lugar, a comparação sistemática entre os dois grupos peca por não testar o efeito espúrio destas relações, isto é, a existência de outros fatores subjacentes ao cruzamento por qualificação. Trata-se de uma primeira análise exploratória dos dados obtidos, que será desenvolvida no futuro próximo. Não obstante as limitações, a análise efetuada leva a traçar um duplo perfil da emigração portuguesa.

Por um lado, os emigrantes mais qualificados são ligeiramente mais novos e mais equilibrados em termos de sex ratio do que os menos qualificados. Emigram em grande parte para o Reino Unido, mas em termos comparativos apresentam um peso superior nos países da CPLP - nomeadamente Angola, Moçambique e Brasil. A maioria encontra-se na sua primeira deslocação emigratória e iniciou-a, na maior parte dos casos, por se tratar de uma nova experiência, mas também por considerar que não tinha futuro em Portugal e pelas fracas oportunidades de progressão na carreira profissional. No país de destino, a sua inserção profissional dá-se especialmente no setor das atividades financeiras e nos serviços às empresas, seguido pelo setor da educação. As suas principais dificuldades de integração são, tal como no grupo dos menos qualificados, o custo de vida, o acesso à habitação e o clima. No que respeita às suas relações com Portugal, cerca de metade envia remessas e embora tendencialmente não o façam com uma base mensal, enviam valores mais elevados que os menos qualificados. A maioria visita Portugal uma vez a cada três ou seis meses. No país de destino, utilizam os media para comunicar com os familiares e leem frequentemente jornais online portugueses. Por fim, no que concerne aos planos para o futuro, os emigrantes mais qualificados apresentam-se maioritariamente indecisos.

Por outro lado, existe uma emigração menos qualificada, ligeiramente mais velha e mais assimétrica em termos de distribuição por sexo. Esta emigração tem como principal destino a Europa, em geral, e o Reino Unido, em particular. Os que emigraram para estes países fizeram-no maioritariamente porque consideravam que não havia futuro em Portugal, mas também por insatisfação com o salário e por um desejo de realizar novas experiências. Esta foi, em grande parte dos casos, a sua primeira experiência de emigração. No que respeita à sua integração laboral, encontram-se inseridos sobretudo 
nas áreas da construção civil e obras públicas, no comércio, nos serviços de alojamento, restauração e transportes. Enunciam como principais dificuldades o custo de vida no destino, o acesso à habitação e o clima. Nas relações com Portugal, cerca de metade dos portugueses menos qualificados enviam remessas, tendencialmente com uma periodicidade mensal, e o mais comum é visitarem Portugal uma vez por ano. Utilizam os media para comunicar com a família e assistem a canais de televisão portugueses. Grande parte destes emigrantes planeia permanecer no país de destino, enquanto uma proporção ligeiramente inferior tenciona regressar a Portugal.

\section{Referências bibliográficas}

ARAúJO, E. R. (2007). Why Portuguese Students Go Abroad to Do Their PhDs. Higher Education in Europe, 32(4), 387-397.

AZEVEDO, J. (2014). Emigração portuguesa qualificada no contexto europeu - Resultados preliminares. Comunicação à Conferência Emigração Portuguesa Contemporânea, ISCTE-IUL, Lisboa, 12 março 2014.

BLITZ, B. K. (2014). Migration and Freedom. Mobility, Citizenship and Exclusion. Cheltenham: Edward Elgar Pub.

CAndeIAS, P., Ferreira, B., \& Peixoto, J. (2014). Emigração Portuguesa: o que temos vindo a estudar e o que nos falta saber - uma análise bibliométrica entre 1980 e 2013. População e Sociedade, 22, 10-31.

Cogo, D., \& Badet, M. (2013). De braços abertos... A construção midiática da imigração qualificada e do Brasil como país de imigração. In E. Araújo, M. Fontes \& S. Bento (Eds.), Para um debate sobre Mobilidade e Fuga de Cérebros (eBook) (pp. 32-57) Braga: CECS - Centro de Estudos de Comunicação e Sociedade.

COLIC-PEISKER, V. (2008). Migration, Class, and Transnational Identities. Croatians in Australia and America. Urbana/Chicago: University of Illinois Press.

DeliCAdo, A. (2010). Going Abroad to do Science: Mobility Trends and Motivations of Portuguese Researchers. Science Studies, 23(2), 36-59.

DELICADO, A. (2011). The consequences of mobility: careers and work practices of Portuguese researchers with a foreign PhD degree. In F. Dervin (Ed.), Analysing the 
consequences of international academic mobility (pp. 163-180). Newcastle: Cambridge Scholars Publishing.

DEliCADO, A., \& Alves, N. d. A. (2013). "Fugas de Cérebros", "Tetos de Vidro" e "Fugas na Canalização": mulheres, ciência e mobilidade. In E. Araújo, M. Fontes \& S. Bento (Eds.), Para um debate sobre Mobilidade e Fuga de Cérebros (eBook) (pp. 8-31). Braga: CECS - Centro de Estudos de Comunicação e Sociedade.

Dillman, D. A., Smyth, J. D., \& Christian, L. M. (2014). Internet, Phone, Mail, and Mixed-Mode Surveys. The Tailored Design Method. (4th ed.) New Jersey: Wiley. EMíliA, A., \& Ferreira, F. (2013). A "Fuga de Cérebros": um discurso multidimensional. In E. Araújo, M. Fontes \& S. Bento (Eds.), Para um debate sobre Mobilidade e Fuga de Cérebros (eBook) (pp. 58-82): CECS - Centro de Estudos de Comunicação e Sociedade.

FARIA, A. M. A. (2012). A emigração portuguesa qualificada: circulação e redes de emigrantes como contributo para o país de origem. (Dissertação de Mestrado, Universidade do Minho). Disponível em: http://repositorium.sdum.uminho.pt/ handle/1822/23323

FONTES, M. (2007). Scientific mobility policies: how Portuguese scientists envisage the return home. Science and Public Policy, 34(4), 284-298.

FONTES, M., \& Araújo, E. (2013). (I) Mobilidades e redes científicas internacionais: Contextos e relações em mudança. In E. Araújo, M. Fontes \& S. Bento (Eds.), Para um debate sobre Mobilidade e Fuga de Cérebros (eBook) (pp. 58-82): CECS - Centro de Estudos de Comunicação e Sociedade.

GOMES, R. (coord.) et al. (2015). Fuga de cérebros: retratos da emigração portuguesa qualificada. Lisboa: Bertrand.

INGLEHART, R. (1977). The Silent Revolution - Changing Values and Political Styles Among Western Publics. New Jersey: Princeton University Press.

INGLEHART, R. (1990). Culture Shift in Advanced Industrial Society. New Jersey: Princeton University Press.

LOPES, J. T. (2014). Geração Europa? Um estudo sobre a jovem emigracão qualificada para França. Lisboa: Mundos Sociais.

MALHEIROS, J. (2010). Portugal 2010: o regresso do país de emigração? Notas e reflexões. Janus - anuário de relações exteriores, 2(1), 133-142.

MARQUES, J. C. (2010). A emigração portuguesa em tempos de imigração. POLÍGONOS. Revista de Geografía (20), 115-129. 
OECD-UN-DESA (2013). World Migration in Figures. OECD-United Nations Department of Economics and Social Affairs. Disponível em: (www.oecd.org/els/mig/ World-Migrationin-Figures.pdf)

PEIXOTO, J. (2012). A emigração portuguesa hoje: o que sabemos e o que não sabemos. (SOCIUS Working Paper n. ${ }^{\circ}$ 5). Lisboa: ISEG.

PEREIRA, A. P. F. (2007). Leitores de Língua e Cultura Portuguesas no Estrangeiro. Experiências de Leitorado e Percursos Profissionais no Estrangeiro. (Dissertação de Mestrado, Faculdade de Ciências Sociais e Humanas, Universidade Nova de Lisboa (FSCH-UNL)). Disponível em: http://cesnova.fcsh.unl.pt/cms/files/publicacoes/PUB4e08c66c5f5e2.pdf

Pereira, C., Pinto, N., \& Pires, R. P. (2015). Enfermeiros portugueses no Reino Unido 2014. OEm Fact Sheets, n. ${ }^{\circ}$ 3: Observatório da Emigração, CIES-IUL, ISCTE-IUL doi: 10.15847/CIESOEMFS032015-pt-en.

PIRES, R. P., Pereira, C., Azevedo, J., \& Ribeiro, A. C. (2014). Emigração Portuguesa. Relatório Estatístico 2014. Lisboa: Observatório da Emigração e Rede Migra, Instituto Universitário de Lisboa (ISCTE-IUL), CIES-IUL, e DGACCP.

PIRES, R. P., Pereira, C., Azevedo, J., Santo, I. E., Vidigal, I., \& Ribeiro, A. C. (2015). Emigração Portuguesa. Relatório Estatístico 2015. Lisboa: Observatório da Emigração e Rede Migra, CIES-IUL, ISCTE-IUL, e DGACCP.

RiBeIRO, J. S., Conceição, C., Pereira, J., Leone, C., Mendonça, P., Temido, M., Vieira, C. P., \& Dussault, G. (2013). Health professionals moving to... and from Portugal. Health Policy, 114(2-3), 97-108.

TAYlOR, D. M., Wright, S. C., Moghaddam, F. M., \& Lalonde, R. N. (1990). The Personal/Group Discrimination Discrepancy. Perceiving My Group, but not Myself, to be a Target for Discrimination. Personality and Social Psychology Bulletin, 16(2), 254-262. 
(Página deixada propositadamente em branco) 